\title{
THE DESTRUCTION OF THE OZONE LAYER AND ITS HARM TO HUMANS, PLANTS, ANIMALS AND THE ENVIRONMENT
}

\author{
Omid Moqimzai \\ Department of Agronomy, Agriculture Faculty \\ Faryab University, Faryab, Afghanistan
}

\begin{abstract}
The ozone layer or ozonosphere, a region of the stratosphere layer in the Earth's atmosphere, with a relatively high concentration of it, is located at a height of $48-19 \mathrm{~km} \mathrm{(30-12} \mathrm{miles)} \mathrm{above} \mathrm{the} \mathrm{Earth's} \mathrm{surface.} \mathrm{The}$ ozone layer is a layer in the atmosphere of the planet and in the stratosphere's stratum that consists of ozone-rich malicles, which surrounds the planet like a bubble and acts as a flatter against the ultraviolet radiation of the sun, called UV-B Plays. It is a very strong light that shines from the sun and has very serious consequences for the health of humans, plants, animals and the environment. The purpose of the study is to recognize the classes of ozone, generally scientists have divided the ozone layer into $d$ and the division, bad ozone and good ozone. Bad ozone ozone refers to that part of the more than 10 kilometers at the end of that ozone is formed by human activity and is located in the troposphere layer. As a result, this kind of ozone is known as air pollution. And it is dangerous to humans, animals, plants and the environment.
\end{abstract}

Keywords - Stratosphere, Montreal, Therposphere, Ultraviolet

\section{INTRODUCTION}

The ozone layer is a layer in the atmosphere of the planet and in the stratosphere's stratum that consists of ozone-rich malicles, which surrounds the planet like a bubble and acts as a flatter against the ultraviolet radiation of the sun, called UVB Plays. It is a very light that shines from the sun and has very serious consequences for the health of humans, plants, animals and the environment (6: 34-35).

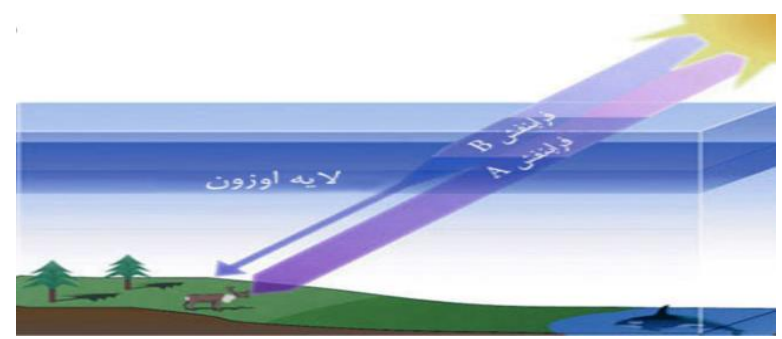

The stratosphere layer is located in the ground after the troposphere layer, and begins at a height of 10 to 20 kilometers, and continues at a height of 40 to 50 kilometers. Generally, scientists have divided the ozone layer into two parts, bad ozone and good ozone. Bad ozone refers to that part of the ozone, which is at an altitude of more than 10 kilometers, which is formed by human activity and located in the troposphere layer. In general, this type of ozone is known as air pollution. And it is dangerous to humans, animals, plants and the environment (2: 202-203).

Good ozone is also called tropospheric ozone. This type of ozone is naturally occurring and is the very vital layer that protects the earth from ultraviolet radiation.

After the Industrial Revolution, due to human activities, part of the ozone layer, located in the Antarctic region of the Earth, has been destroyed, causing sun damage to the ground and causing much damage in those areas. It was noted that after years of scientific studies by scientists, detailed information was obtained about the thinning of the ozone layer and ways to improve it, and global efforts to protect the ozone layer intensified. That's why for the first time in 1985, world countries gathered in the city of Viana, Austria, and signed a legal framework for protecting the ozone layer, the Viana Convention. Followed in 1987 in Montreal, Canada, efforts are environmentally friendly and countries concluded a treaty called (the Montreal Protocol) signed. This protocol, of its kind, is perhaps the most important achievement of countries in environmental matters, especially the protection of the ozone layer. As it obliges member states to ban the use of ozone-depleting substances over a specified timetable. Currently, more than 197 countries have signed the protocol.

United States Space Agency Reports (NASA) Shows that in 2015, the ozone hole reached 28.2 million square kilometers compared to 2014 was 24.1 million square kilometers more. This is a serious warning for living organisms on earth. 


\section{International Journal of Engineering Applied Sciences and Technology, 2020 \\ Vol. 5, Issue 3, ISSN No. 2455-2143, Pages 10-14 \\ Published Online July 2020 in IJEAST (http://www.ijeast.com)}

\section{BACKGROUND INFORMATION}

\section{A. What is ozone}

Ozone is a Greek word meaning smell and especially odor. Ozone is a malicolic with three oxygen atoms.

The ozone layer or ozone layer of the layer is at a height of 20 to $30 \mathrm{~km}$ in the Earth's surface (which varies depending on seasonal and climatic conditions), with a thickness of 3 millimeters in the stratosphere of the Earth's atmosphere, with a high concentration of ozone molecule (O3) Was discovered in 1913 by two French physicists named Charles Fabry and Henry Bowison. This layer, which absorbs 95$99.9 \%$ of the ultraviolet light of the sun, will make life on Earth. The ozone layer absorbs ultraviolet rays and sends them into infrared rays and sends them to Earth's surface.

Ozone with the chemical formula $\mathrm{O} 3$ A relatively unstable malicolus, consisting of three autogas with a chemical symbol O Is formed. The ozone layer has emerged from the accumulation of these malicles. Although this layer covers a small part of the planet's air, it is very important, and it can continue to live on the planet. This malicol reacts between the polyvinyl alcohol and the chemical fertilizer $\mathrm{O} 2$ And sunlight comes about. This is an effective process that occurs in the stratosphere layer at a height of $15-50 \mathrm{~km}$ above the surface (3: 122-123).

The ozone layer or ozonosphere, a region of the stratosphere layer in the Earth's atmosphere, with a relatively high concentration of it, is located at a height of 48-19 km (3012 miles ) above the Earth's surface .

About $90 \%$ of the ozone is located between $17-10 \mathrm{~km}$ above the Earth's surface and reaches $50 \mathrm{~km}$. The ozone molecules in this part of the planet's atmosphere form the ozone layer. The rest of the oocytes are also in the globular troposphere layer .

\section{B. Ozone and ultraviolet}

Ultraviolet, produced by solar radiation, can cause skin cancer, ocular cataracts, damage to the body's gravity, and a negative effect on plant growth, if it reaches the surface .

The ultraviolet wavelength of 400-280 (a billionth of a meter) is. Ozone and oxygen molecules that are in the stratosphere absorb ultraviolet rays of the sun and, like a shield, prevent them from entering the Earth's surface . Ozone oxidants can absorb 99.9-95\% of ultraviolet rays, especially ultraviolet carbon-bromine, which are the most energetic ultraviolet rays that cause biological damage. According to this, the role of ozone surveillance is so critical that scientists say life on Earth without ozone layer is not possible .

$$
\mathrm{O} 3+\mathrm{UV} \rightarrow \mathrm{O} 2+\mathrm{O}
$$

Molecular atomic oxygen + oxygen $\rightarrow$ Ultraviolet + Ozone

$$
\mathrm{O} 2+\mathrm{O} \rightarrow \mathrm{O} 3+\mathrm{IR}
$$

Infrared + ozone $\rightarrow$ Atomic Oxygen + Malic Oxygen

With the arrival of gas (CFC) To the stratosphere, the chlorine present in this compound can react with ozone in the air and bring a compound called chlormonoacid (5: 183-185).

In the early 1970s, prohrachers began to study the effects of different chemicals on the ozone layer, in particular carbon, fluorine, chlorine (CFC) That contain chlorine. If chlorine reaches the stratosphere from hydrophilic pools, industrial plants, sea salt and volcanoes, it can easily be combined with rain on the troposphere floor. But the chlorine in chlorine, fluorine, carbon (CFC). Due to their high stability, these compounds do not dissolve in rain water, and as time goes on, they move towards the stratosphere, and no formal process can prevent this. These compounds are usually heavier than air, but move in a process that lasts about 2 to 5 years (1: 212114).

In the early 1930s, compounds such as chlorine, fluorine, carbohydrates ( CFC) Were invented in the United States and used in the industry and in homes. These compounds were found in the stratosphere, and the chlorine and bromine elements contained in them during chemical reactions led to a gradual degradation of the ozone layer, especially the ozone layer in the South Pole Dropped sharply .

Halocarbons are also other threatened ozone-depleting stratospheric materials, and, by releasing chlorobemes, they destroy the ozone layer. Also, some of the ozone depleting substances in air vehicles, glaciers, AC ( Air condition ) And capsules are volcanic. In 1978 the United Nations global agreement to stop production, sale and gases chlorine, fluorine, carbon ( CFC) Are provided. This agreement is known as the Montreal Convention or the Montreal Protocol (4: 89-90).

\section{Montreal Protocol}

In September 2014, the United Nations for the first time in the past thirty-five years, researchers have confirmed that the ozone layer, which has been at risk in some parts of the world, has been showing signs of recovery and recovery, since the year From 2000 to 2013, ozone levels in parts of the world grew by $4 \%$. According to the researchers, the reason for the beginning of the process of repair of the ozone layer is that since the late 1980 's the use of some harmful chemicals to the ozone layer has gradually been eliminated throughout the world, and for the time being these gases are used in a variety of glaciers and spray types. . Still severe restrictions on chlorine, fluorine, carbon ( CFC ) Has led the World Meteorological Organization to conclude that the ozone 


\section{International Journal of Engineering Applied Sciences and Technology, 2020 \\ Vol. 5, Issue 3, ISSN No. 2455-2143, Pages 10-14 \\ Published Online July 2020 in IJEAST (http://www.ijeast.com)}

cavity will improve by 2045 . But the American Space Agency ( NASA ) Says that two-thirds of the ozone layer will be destroyed not only over the Antarctic, but around the globe until 2065

\section{How is the ozone layer destroyed?}

Ozone Depleting Materials ( ODS ) Are chemicals that have the potential to react to ozone-rich malts in the stratospheric layer. This material is made from hydrocarbons Kolur, flora, or bromide and are composed of chlorine, fluorine, carbon ( CFC ) Hydrochloric Flora Carbon ( HCFCs), Hydrobromofluorocarbons ( HBFCs ), Bromocloromethane, methyl chlorofluoride, tetrachloride carbonates, methyl bromide and the like, which are mostly used in refrigerated industries such as glaciers, AC ( Air condition), Foam industry or foaming of fire-retardants in sprays, in agricultural industries, etc. (1: 112-113).

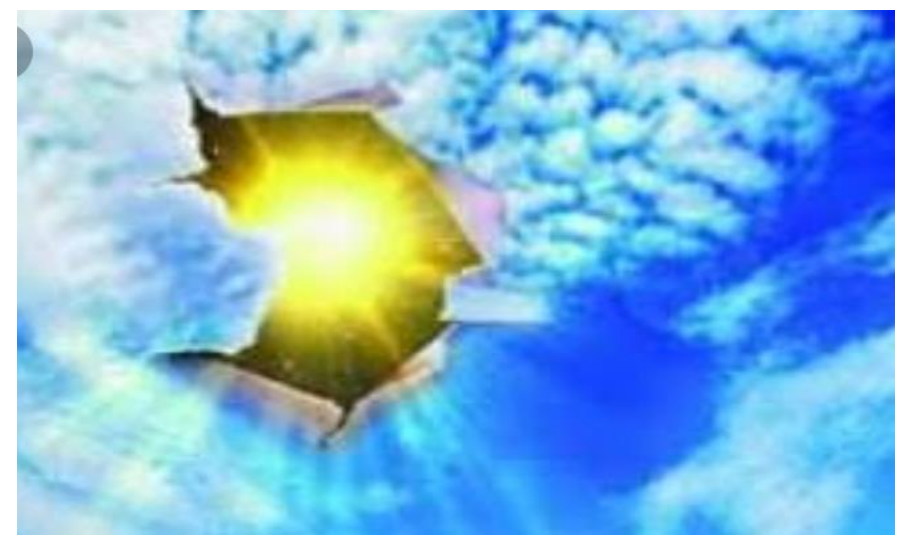

Figure (2) Destruction of the ozone layer in the South Pole

\section{E. Its effects on humans}

Sunburn, inflammation, and dry skin, and in severe forms such as skin cancer, changes in the immune system of the human body, the development of eye infections such as cataracts in humans.
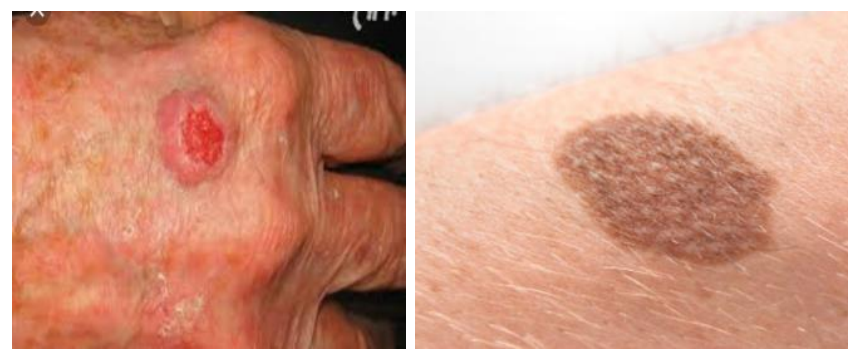

Figure 3 Skin Cancer Caused by sunburn

\section{F. Its effects on agriculture and livestock}

1. Disruption of the path of the birds
2. Changes in the animal's immune system

3. Creation of eye infections in some animals

4. Global warming

5. Creating droughts and destroying agricultural products in proportion to the shortage of groundwater.

6. Climate change

\section{OZONE LAYER PROTECTION IN AFGHANISTAN}

The Government of the Islamic Republic of Afghanistan, in June 2004, approved the Montreal Protocol and was recognized as the 188th member. Ozone Layer ( ODSs ). Which is controlled by the Office of National Conservation of the Ozone Layer Protection Office in Afghanistan, mainly in glaciers, AC ( Air condition ) Fixed and mobile, industrial, fire equipment (fire), sprays, insecticides and sponges used for fall (7: 112-113).

Implementation of the first phase of the Montreal Protocol in Afghanistan ending the use of chlorofluorocarbons ( CFCs ), Halogens and carbon tetrachloride ( CTC ) Until 2010, which fortunately Afghanistan has achieved this goal. The Ozone Layer Office of the National Environmental Office, in close cooperation with relevant bodies such as the Department of Customs, the Ministry of Labor and Social Affairs and other entities, was able to import gas (by 2010 ) CFC Including R12 ) That led to the prohibition on implementing the treaty's Afghanistan Country Award in 2008, 2009, 2011 and 2012 to obtain.

The second phase of the Montreal Protocol and the current plan by the Office of the Ozone Office of the National Environmental Protection Agency, in accordance with the commitments made by the Montreal Protocol, is the gradual elimination of hydrochlorofluorocarbons or HCFC It is necessary to prohibit the import and use of these gases by $2040(2: 112-113)$.

\section{A. Effects of Ozone Layer on Air and Environment Water}

Environmental impacts Huge amounts of hazardous waste generated every year have become more worrying. In 1983, 266 million tons of hazardous waste were produced, with the 1987 Montreal Protocol establishing a plan to reduce ozone-depleting chemicals, which has had a positive impact.

Earth warming is a systematic increase in heat of the earth, mainly due to greenhouse gas emissions, ozone is a greenhouse gas and plays an important role in the global climate change of water and the environment. The environmental effects of ozone depletion include: 


\section{International Journal of Engineering Applied Sciences and Technology, 2020 \\ Vol. 5, Issue 3, ISSN No. 2455-2143, Pages 10-14 \\ Published Online July 2020 in IJEAST (http://www.ijeast.com)}

1. Destruction and disruption of food chain in land ecosystems.

2. Increased eye cataract and various types of diseases. Eye irritation in the environment.

3. The occurrence and increase of types of skin cancer

4. Disappearance of infants of sea creatures and fish

5. Destruction of plants and trees

6. Increased infectious diseases due to weakening of the immune system One of the organisms that is very sensitive to ultraviolet rays is phytoplankton. These aquatic plants are located near the surface of the water and are exposed to solar radiation, reducing their production leads to many consequences, because they directly and indirectly make up almost all fish (8: 202203).

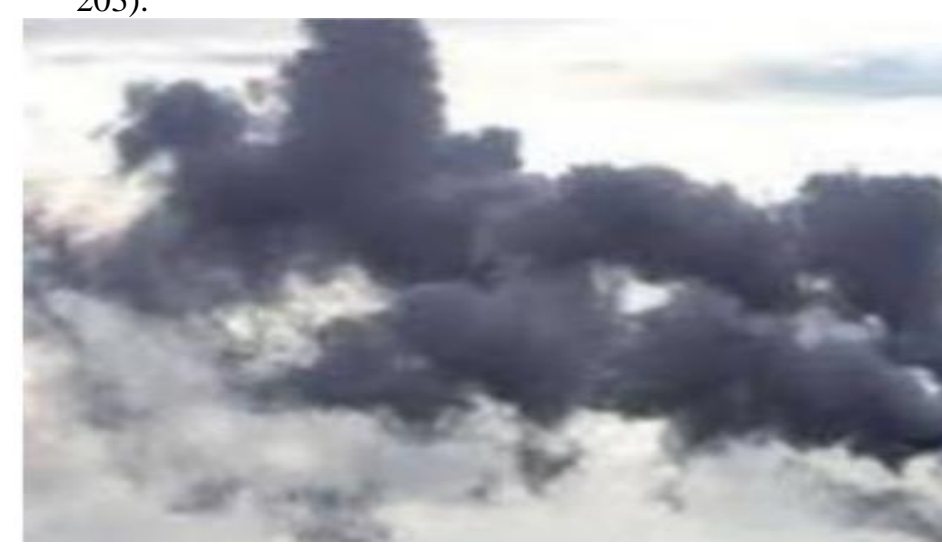

Figure 4. Effects of ozone depletion on air

\section{B. Why is the ozone layer in Antarctica damaged?}

There is a question that, although there are more land in the northern hemisphere and industrial pollution is also found in most parts, why is the largest ozone layer in the Antarctica?

According to scientists, one of the reasons for the greater vulnerability of the ozone layer is in the southern part of the polar ring, which absorbs dye-colored floroms of the abandoned by industrial activities. Another is that clouds with small ice crystals are created in the highest stratosphere due to the extremely cold and frosty weather of the night in Antarctica. These crystals play a catalyst or accelerator, and cause compounds containing ozone-depleting substances to break into clouds and become active in chlorine. When the sun begins to shine from a long night, its exposure to radiation, chlorine monoxide, can damage the ozone layer. In addition, another factor that causes the destruction of the ozone layer in the southern plain is the movement and rotation of polar winds without any obstacles throughout this vast and frozen area, while this factor in the Arctic is due to higher temperatures and less formation Ice clouds are very weak.
C. How can we protect the ozone layer?

1. When buying refrigerators, such as refrigerators and air ducts, try to use appliances that are gas HCFC Not to be used

2. Use the items to indicate the energy efficiency or use the eco-friend.

3. Do not clean the refrigerator with knife and knife.

4. Contact the professional when installing the air conditioner.

5. As far as possible, avoid having children in the sun when the sun is hot. If you are sun-torn at sunset times, take a lot of sunscreens.

\section{CONCLUSION}

Layer Ozone is a layer in the atmosphere of the planet and in the stratosphere's stratum that consists of ozone malicles and circles around the planet like a bubble and acts as a flatter against the ultraviolet radiation of the sun, called UVB Plays. It is a very light beam that sunshine and has very serious consequences for the health of humans, plants, animals and the environment. In the early1970s, prohrachers began to study the effects of different chemicals on the ozone layer, especially chlorine, fluorine, Carbon ( CFC) That contain chlorine. If chlorine reaches the stratosphere from swimming pools, industrial plant sea salt and volcanoes, it can easily be combined with in or he troposphere floor. But chlorins that are in chlorine, fluorine, carbon ( CFC) Exist due to the sustainability of many of these compounds are poorly soluble in water, and over time they move toward Astratvsfyr floor and no Frayndtbyy cannot be prevented this. These compounds are usually heavier than air, but move in a process that lasts about 2 to 5 years.

Environmental effects The huge amounts of hazardous waste generated every year have become more worrying. In 1983, 266 million tonnes of hazardous waste were produced, with the 1987 MontrealProtocol establishing a plan to reduce ozone-depleting chemicals that have produced positive effects.

\section{A. Findings ( result )}

Scholarly article entitled forth (destruction of the ozone layer and its harm on plants, animals and the environment) using new sources and scientific and technical cooperation and advice combined with great professors were completed Fortunately Tips was brought forward as scientific findings.

First: Protect against ultraviolet radiation from the sun, because it is a very strong light that shines from the sun and has very serious consequences for the health of humans, plants and animals . 


\section{International Journal of Engineering Applied Sciences and Technology, 2020 \\ Vol. 5, Issue 3, ISSN No. 2455-2143, Pages 10-14 \\ Published Online July 2020 in IJEAST (http://www.ijeast.com)}

Second, as the destruction of the ozone layer is prevented, usually from gas chlorine, fluorine, carbon ( CFC ) Does not take place.

Thus, the present study do not only lifts our insight and knowledge in the area led the way, but accurate information possible theoretical and practical than ever that really aware of some issues such as the ozone layer, roll it protects people, plants and Hyvatat of ultraviolet radiation, prevent the destruction of the ozone layer ... that man learns and teaches.

\section{B. Conflict}

The ozone layer is a layer in the atmosphere of the planet and in the stratosphere's stratum that consists of ozone-rich malicles, which surrounds the planet like a bubble and acts as a flatter against the ultraviolet radiation of the sun, called UVB Plays . It is a very light light beam that sunshine and has very serious consequences for the health of humans, plants, animals and the environment.

The purpose of the study is to recognize the classes of ozone, its roll over humans, plants and animals, preventing the destruction of the ozone layer, the lack of use of chlorine gas, fluorine and carbon ( CFC ).

\section{Offers}

1. When buying refrigerators, such as refrigerators and air ducts, try to use appliances that are gas HCFC Not to be used .

2. Use the items to indicate the energy efficiency or use the eco-friend .

3. Do not clean the refrigerator with knife and knife .

4. During installation AC (Air condition) Contact professional people.

5. As far as possible, avoid the cultivation and transfer of children during hours of intense sunlight. If you are suntorn at sunset times, take a lot of sunscreens.

\section{REFERENCE}

[1] Ahmadzai, Abdul Baghi. (1387). Set Facts paced environment. Afghanistan: Publications Afghan National Environmental Protection Agency .

[2] taghizadeh Ansari, Mustafa. (1376). Environmental Criminal Law . Iran : Publication of the side .

[3] Ansari Taghizadeh, Mostafa (1374). Environmental Criminal Law . Iran : Publication of the side .

[4] Second Reza . Year (1382). Subglobalization . Iran : Publishing Aghili Publishing.

[5] United Nations Population Fund. Year ) 1995 (Summary of the program of the International Conference on Population and Development. Iran : Tehran Publishing House .

[6] Fazel, Mandana (1384). The role of the government in an ever-changing world. Iran : Institute of Business Studies and Publications .

[7] Farshad, Bashirzadehan (1384). Judicial protection of the environment . Iran : Nashrni Publishing .

[8] Ghasemi, Nasser. (1376). Environmental Criminal Law . Iran : Jamal al-Haq Publications .

[9] NOAA. (2017).Ozone Basics.

[10] Naryanan ,D.L. ,Saladi,R.N.(2010).Ultraviolet radiation and skin cancer. international Journal of Dermatology.

[11] Ungar ,Sheldon.(2000).Knowledge,ignorance and the popular culture(climate change versus the ozone hole).public Understanding of Science.

[12] Grundmann,Reiner(2007).Climate Change Knowledge Politics.Enviromental Politics.

[13] Solmon ,Susan ,et al.(2016).Emergence of Healing in the Antractica.National Resource Journal.

[14] Morrisette,Peter M.(1989). Evolution of Policy Responses to Stratospheric Ozone Depletion. National Resource Journal. Retrieved 2010. 